\title{
Capsule Endoscopy: Pitfalls and Approaches to Overcome
}

\author{
Seung Han Kim $\mathbb{1}$ and Hoon Jai Chun * \\ Division of Gastroenterology and Hepatology, Department of Internal Medicine, Korea University College of \\ Medicine, Seoul 02841, Korea; kimseunghan09@gmail.com \\ * Correspondence: drchunhj@gmail.com; Tel.: +82-2-920-6555
}

check for

updates

Citation: Kim, S.H.; Chun, H.J.

Capsule Endoscopy: Pitfalls and

Approaches to Overcome. Diagnostics

2021, 11, 1765. https://doi.org/

10.3390/diagnostics11101765

Academic Editors: Vito

Domenico Corleto and

Hajime Isomoto

Received: 17 August 2021

Accepted: 21 September 2021

Published: 25 September 2021

Publisher's Note: MDPI stays neutral with regard to jurisdictional claims in published maps and institutional affiliations.

Copyright: (c) 2021 by the authors. Licensee MDPI, Basel, Switzerland. This article is an open access article distributed under the terms and conditions of the Creative Commons Attribution (CC BY) license (https:/ / creativecommons.org/licenses/by/ $4.0 /)$.

\begin{abstract}
Capsule endoscopy of the gastrointestinal tract is an innovative technology that serves to replace conventional endoscopy. Wireless capsule endoscopy, which is mainly used for small bowel examination, has recently been used to examine the entire gastrointestinal tract. This method is promising for its usefulness and development potential and enhances convenience by reducing the side effects and discomfort that may occur during conventional endoscopy. However, capsule endoscopy has fundamental limitations, including passive movement via bowel peristalsis and space restriction. This article reviews the current scientific aspects of capsule endoscopy and discusses the pitfalls and approaches to overcome its limitations. This review includes the latest research results on the role and potential of capsule endoscopy as a non-invasive diagnostic and therapeutic device.
\end{abstract}

Keywords: capsule endoscopy; magnetic assisted capsule endoscopy; locomotion; diagnostic yield; completion rate; retention; interpretation

\section{Introduction}

Since capsule endoscopy was introduced in the early 2000s, capsule endoscopy has played an important role in evaluating small intestinal lesions [1]. Capsule endoscopy is recommended as the first-line test for obscure gastrointestinal bleeding. It is effectively used as a diagnostic tool for small bowel diseases such as Crohn's disease, small bowel tumor, celiac disease, unexplained abdominal pain, and diarrhea [2-4].

Compared to conventional endoscopy, capsule endoscopy is a less invasive examination method that does not require sedation during the examination process and reduces the patient's discomfort. In addition, it enables easy access to structures such as the small intestine that were previously difficult to access.

Capsule endoscopy has continuously improved since it has been applied in clinical practice [5-10]. However, there are still shortcomings that need to be addressed. (1) First, the capsule endoscope cannot be positioned as intended by the examiner. (2) Unlike conventional endoscopes, air cannot be adequately inflated, limiting sufficient observation of the gastrointestinal tract. (3) Due to the device's limitation in the form of a small pill, effective optical technology cannot be easily applied. (4) The quality of the examination is determined by the condition of the intestinal tract, such as poor bowel preparation or air bubbles. (5) Procedures such as biopsy or hemostasis are not possible. (6) There is a risk of capsule retention. (7) It takes considerable time and effort to interpret after the test is performed.

\section{Maneuverability \\ 2.1. Magnetic Navigation System}

One of the disadvantages of capsule endoscopy is the impossibility of operating the device; therefore, it is difficult to observe by adjusting the field of view as desired. This affects the overall miss rate of capsule endoscopy. The miss rates for small bowel tumors, vascular disease, and ulcers were $18.9 \%, 5.9 \%$, and $0.5 \%$, respectively [11]. Efforts have been made to overcome these shortcomings to reduce the overall miss rate. 
The application of magnetic fields in the medical field has long been practiced. Recently, it has been applied and used in neurosurgery and the treatment of cardiac arrhythmias [12,13]. Magnetic assisted capsule endoscopy (MACE) is an examination tool that observes the gastrointestinal tract by control the location of the capsule endoscope swallowed by the patient using a magnetic field in real-time. The magnetic field generated outside the human body makes it possible to adjust a capsule endoscope equipped with a permanent magnet or a magnetizable object using translational and rotational forces [14]. To date, several MACE systems have been developed (Table 1).

Table 1. Comparison of magnetically guided capsule endoscopy.

\begin{tabular}{ccccc}
\hline & MiroCam Navi & $\begin{array}{c}\text { Navicam }{ }^{\text {TM }} \text { Stomach } \\
\text { Capsule System }\end{array}$ & $\begin{array}{c}\text { Magnetic Maneuverable } \\
\text { Capsule }\end{array}$ & $\begin{array}{c}\text { Magnetically Guided } \\
\text { Capsule Endoscopy }\end{array}$ \\
\hline Company & $\begin{array}{c}\text { Intromedic, Seoul, } \\
\text { South Korea }\end{array}$ & $\begin{array}{c}\text { Ankon Technologies, } \\
\text { Wuhan, China }\end{array}$ & $\begin{array}{c}\text { Siemens Healthcare, } \\
\text { Given Imaging, } \\
\text { Yoqneam, Israel }\end{array}$ & $\begin{array}{c}\text { Erlangen, Germany } \\
\text { and Olympus Medical } \\
\text { Corp, Tokyo, Japan }\end{array}$ \\
Type & $\begin{array}{c}\text { Hand-held magnetic } \\
\text { field generators }\end{array}$ & $\begin{array}{c}\text { Robotic magnetic } \\
\text { capsule guidance } \\
\text { system }\end{array}$ & Hand-held magnetic field & Multicoil guidance \\
system & generators & N/A \\
Human application & Yes & Yes & Yes & 2010 \\
$\begin{array}{c}\text { Commercially } \\
\text { available }\end{array}$ & Yes & 2013 & N/A & N/A \\
FDA approval & N/A & Yes & N/A & N/A \\
\hline
\end{tabular}

N/A, not applicable.

\subsubsection{Magnetic Maneuverable Capsule}

In 2010, Swain et al. conducted a study to observe the esophagus and stomach by administering MACE by modifying colon-type capsule endoscopy (Given Imaging Ltd., Yoqneam, Israel) [15] to the human body. The capsule endoscopy involved rare earth magnetic materials and operated in an external magnetic field and transmitted images. The weight of the capsule endoscope, including the magnet, was increased to 3.5-7 g. An external paddle-shaped magnet was made to control the capsule in the human body remotely, and it consisted of two rectangular plate-shaped magnets and a handle. The size of the magnet was $100 \times 100 \times 30 \mathrm{~mm}$. The capsule was manipulated in the esophagus for $10 \mathrm{~min}$, and movement or rotation was easy. In the stomach, moving, stopping, and rotating the capsule from the pylorus to the esophageal-gastric junction was possible at any site and did not cause any discomfort to the patient.

\subsubsection{Magnetically Guided Capsule Endoscopy}

In 2010, Siemens Healthcare and Olympus Medical Corp modified the capsule endoscope and developed a $31 \times 11 \mathrm{~mm}$ MACE with a magnet inside [16]. The magnetically guided capsule is steered by the steering system's dynamic magnetic field and gradient. The control system has a shape similar to that of a magnetic resonance imaging scanner, and its approximate size is $1 \times 2 \mathrm{~m}$. It creates a magnetic field force of approximately $100 \mathrm{mT}$ (milliteslas), and in reality, approximately $3-10 \mathrm{mT}$ is used to control the capsule.

\subsubsection{Magnetically Controlled Capsule Endoscopy System}

This system consists of a capsule endoscope, a magnet-controllable robot, a data storage device, and a computer workstation capable of real-time observation and steering (Figure 1) [17]. The size of the capsule is $28 \times 12 \mathrm{~mm}$, and a permanent magnet is built-in. The robotic system allows two rotational and three translational control degrees of freedom. The capsule endoscope takes two pictures per second and transmits them to the data storage device. The robotic system is a C-arm type system with an operating range of more than $50 \times 50 \times 50 \mathrm{~cm}$. The magnetic field generated by the system is up to $200 \mathrm{mT}$ or more. Liao 
et al. conducted a study comparing the diagnostic accuracy of conventional gastroscopy and magnetically controlled capsule endoscopy (MCE) with 350 patients complaining of abdominal discomfort [17]. The mean time to perform MCE was $26.4 \pm 5.1 \mathrm{~min}$, and MCE detected gastric focal lesions in the whole stomach with sensitivity of $90.4 \%$ (95\% confidence interval, CI, 84.7\%-96.1\%), and specificity of $94.7 \%$ (95\% CI, $91.9-97.5 \%$ ), an $87.9 \%$ positive predictive value $(95 \% \mathrm{CI}, 81.7 \%-94.0 \%)$, a $95.9 \%$ negative predictive value ( $95 \%$ CI, $93.4 \%-98.4 \%$ ), and $93.4 \%$ accuracy ( $95 \%$ CI, $90.83 \%-96.02 \%)$.
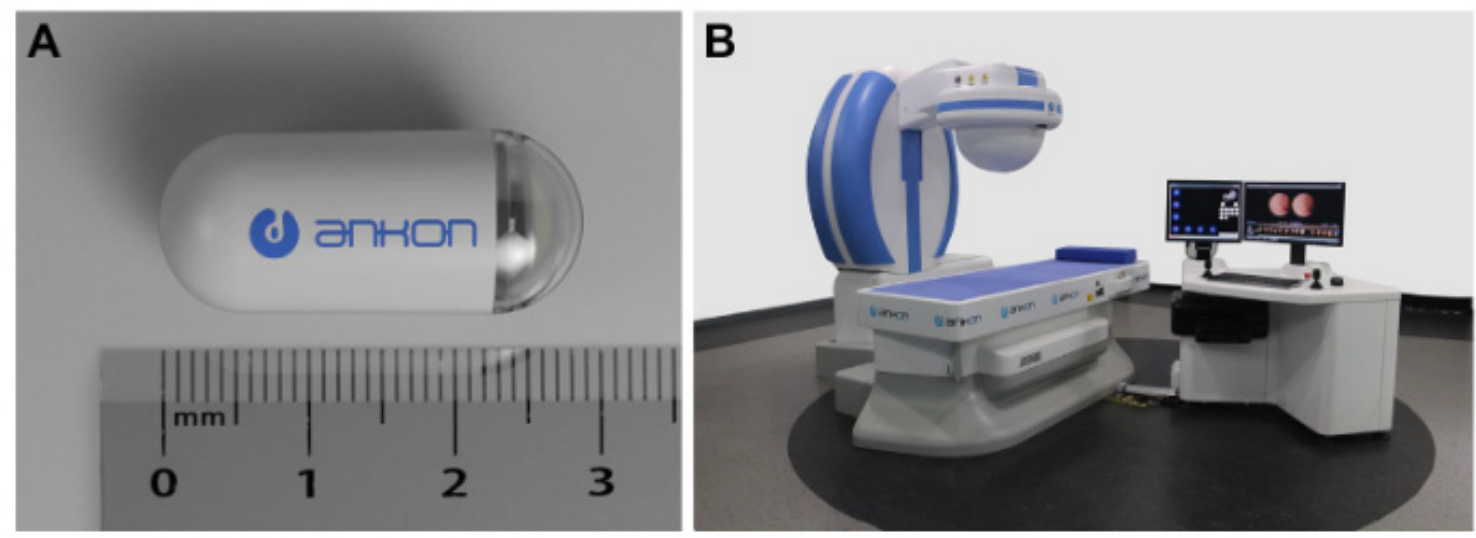

Figure 1. The magnetic-controlled capsule endoscopy system. (A) The NaviCam capsule endo-scope (Ankon Technologies Co, Ltd., Wuhan, China); (B) the NaviCam magnetic control system. Adapted from Liao et al. [17] with permission from Elsevier.

\subsubsection{MiroCam Navi}

MiroCam Navi is a simple system that uses a capsule endoscope and a hand-held magnet to adjust the capsule (Figure 2). The capsule is manufactured by modifying the microcam capsule endoscope for the small intestine. Image data are transmitted to the receiver using electric field propagation, as in other microcam capsule endoscopes. The size of the MiroCam Navi capsule is $25.5 \times 10.5 \mathrm{~mm}$, and the weight is $4.75 \mathrm{~g}$. The length of the hand-held magnet is $26 \mathrm{~cm}$, the width of the handle is $3.5 \mathrm{~cm}$, and the width of the head is $6.5 \mathrm{~cm}$. Ching et al. compared the diagnostic yield of MiroCam Navi and gastroscopy in patients with suspected acute upper gastrointestinal bleeding [18]. A total of 33 patients were included in the study. MiroCam Navi identified more localized lesions than EGD, but the suspected lesions did not reach statistical significance. Capsule endoscopy revealed an additional cause of small bowel bleeding (18\%).

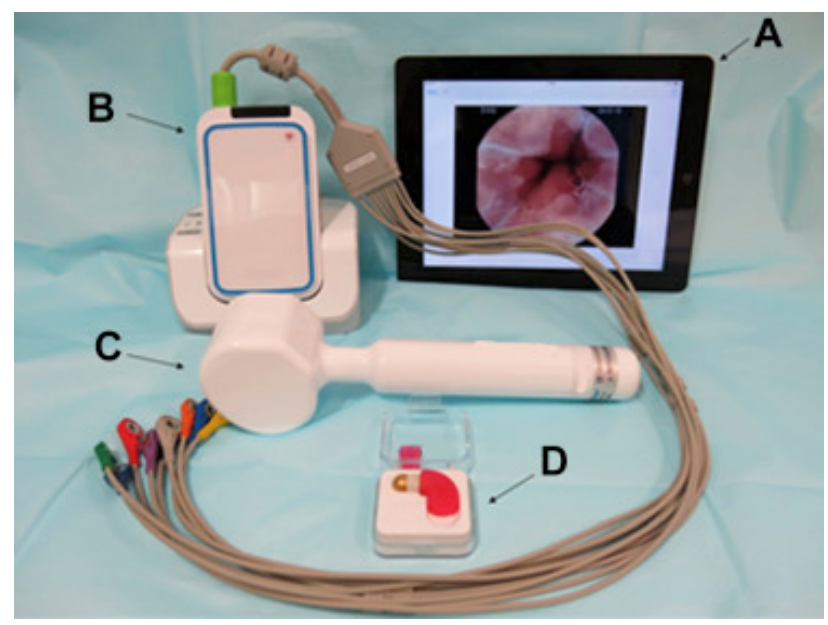

Figure 2. The MiroCam Navi system. (A) real-time viewer; (B) sensor and receiver; (C) hand-held magnet; (D) MiroCam Navi capsule. Adapted from Rahman et al. [19] with permission from Elsevier. 


\subsection{Internal Locomotion System}

Although capsule endoscopy technology has made remarkable progress, numerous unavoidable shortcomings prevent the expansion of capsule endoscopy applications. For example, capsule endoscopy cannot be observed by stopping at a certain area for diagnostic or therapeutic purposes. It is also difficult to return to an area and re-observe. These shortcomings can be overcome by adding a locomotion system to the capsule endoscope. Several research groups have tried to develop a different type of locomotion system for capsule endoscopy. However, it is still in the experimental laboratory stage because of the complexity of the gastrointestinal tract and limited power [20-24]. The actuator is important for propelling the capsule endoscope for an active capsule endoscope system. There are three types of internal locomotion methods.

\subsubsection{Inchworm-Like Capsule Endoscope}

Researchers prefer the friction-based locomotion method because it is based on a simple principle. The inchworm-like method works through three basic movements: anchoring, elongating, and contraction [25]. This action is performed using an actuator made of shape memory alloys (SMA). Cheung et al. presented a mechanism for locomotion and stopping the capsule endoscope in the digestive tract [26,27]. Inspired by the beetle, the authors used a micropatterned adhesive material of polydimethylsiloxane to generate an attraction force between the intestine and the capsule endoscope (Figure 3). The capsule with an inchworm-like mechanism can move back and forth by contracting and elongating the capsule body by sequentially cooling and actuating the SMA wire.

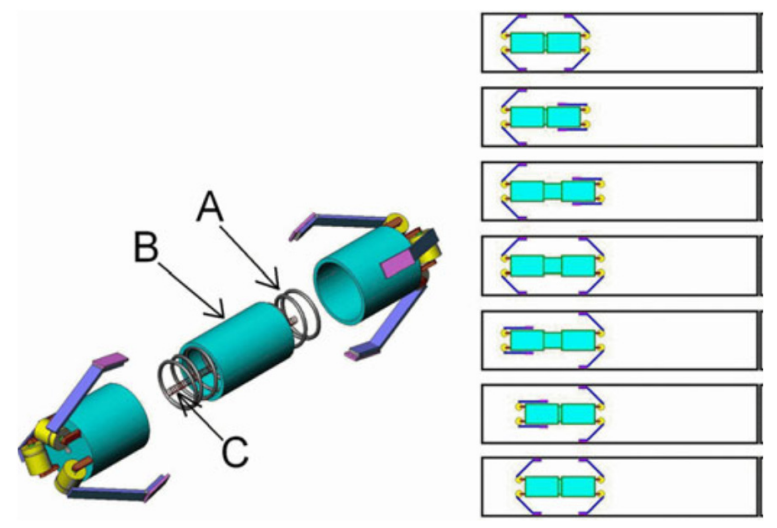

Figure 3. Illustration of inchworm-like locomotion mechanism. (A) compression spring; (B) capsule body; (C) SMA wire. Adapted from Liu et al. [25] with permission from IEEE.

\subsubsection{Paddle/Legged-Based Capsule Endoscope}

Another commonly used friction force-based locomotion method is paddle-based motion. This type of locomotion mechanism originates from canoe paddling. Several paddles or legs are included in the capsule endoscope body, controlled by the actuator and pushed backward on the gastrointestinal tract wall so that the capsule endoscope moves forward. Kim et al. presented a paddling-based capsule endoscope and tested the locomotion of active capsule endoscopy in vitro and in vivo (Figure 4) [22,24]. The locomotive capsule endoscope can easily move forward in the digestive tract by repeating this paddling operation. Therefore, the paddle connected to the outer cylinder protrudes and folds according to the direction in which the inner and outer cylinders are linearly operated along the lead screw. A positional delay from the outer cylinder to the inner cylinder occurs during linear motion owing to the gap between the inner and outer cylinders. As a result, when multiple grooves in the inner cylinder push the end of the paddle relative to the right or left, the paddle rotates at the pivot point for protrusion or folding. 

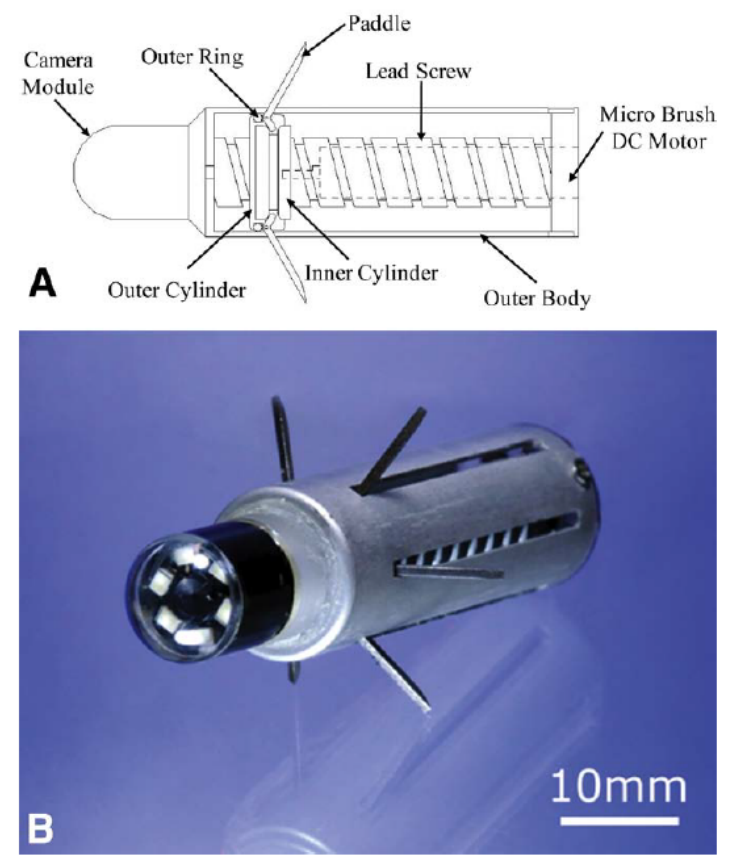

Figure 4. Paddling-based locomotive capsule endoscope. (A) Illustration of the paddling-based locomotive capsule endoscope; (B) the complete paddling-based locomotive capsule endoscope with fully stretched legs. Adapted from Kim et al. [22] with permission from Elsevier.

\subsubsection{Hydrodynamic Force-Based Capsule Endoscope}

Hydrodynamic force-based systems are widely used in the design and manufacture of swimming robots. Therefore, several researchers have used this simple mechanism for the locomotion of the capsule endoscope. Chen et al. worked on a swimming robot capsule endoscope consisting of a steering head and rotational body (Figure 5) [25], divided into a steering mode and a linear mode. A micro motor is used for linear motion, and when the motor rotates, the spiral body rotates, and the capsule moves in a straight line. If the motor is reversed, the capsule endoscope is moved backward. The steering part is activated by the same motor.

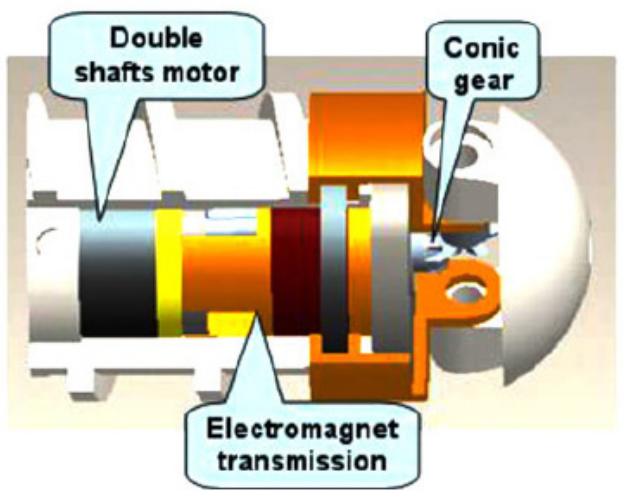

Figure 5. Swimming robotic capsule endoscopy. Adapted from Liu et al. [25] with permission from IEEE.

\section{Air Insufflation}

During capsule endoscopy, the intestinal tract is in a collapsed state, and it is difficult to observe the entire intestinal mucosa through capsule endoscopy. In a conventional endoscope, it is possible to observe the intestinal tract by injecting air to some extent, but it is impossible to inject air with a capsule endoscope [28]. Gorlewicz et al. developed a wireless insufflation capsule and performed ex vivo and in vivo animal experiments [29]. 
The authors provided a means of injecting air with a wireless capsule platform, using biocompatible effervescent chemistry to change the liquid and powder contained in the capsule into gas. They performed experimental evaluation of the amount of gas required to enhance the visualization and movement of the capsule and determined the amount of gas produced from a particular amount of reactant. Pasricha et al. developed a new wirelessly controlled $\mathrm{CO}_{2}$ insufflation system for use in colorectal capsule endoscopy (Figure 6) [30]. The inflatable capsule has two separate compartments connected by a magnetic valve. When triggered, the citric acid solution in the upper part reacts with the sodium bicarbonate in the lower part to generate carbon dioxide. It is released through the exhaust port in the center of the capsule. A permanent external magnet controls this action.
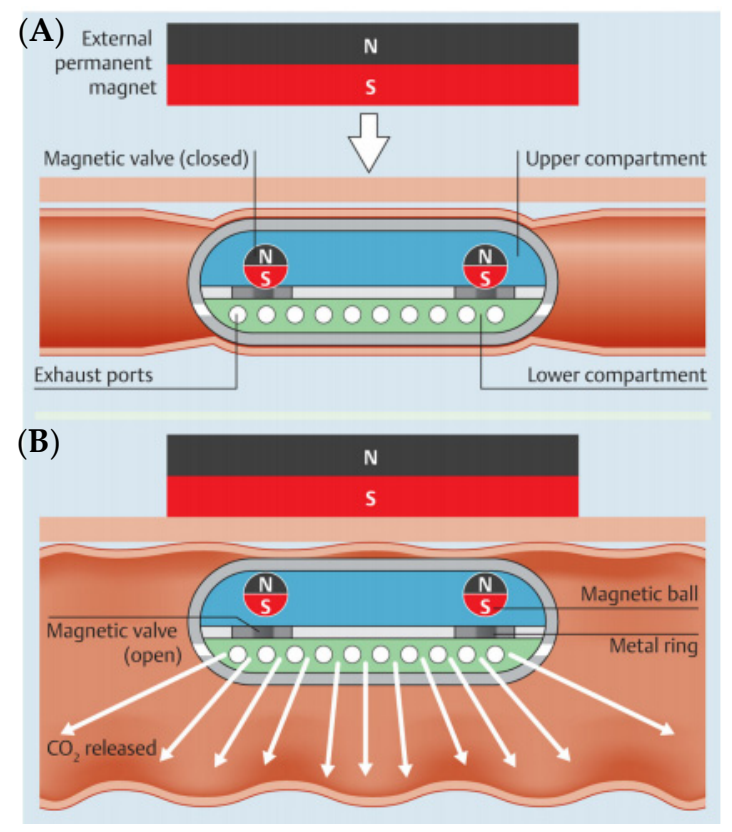

Figure 6. The insufflation capsule with two sections. (A) magnetic valves make a tight barrier between the compartments; (B) when activated with a permanent external magnet, the valves open to permit a mixture of the two reactants, releasing carbon dioxide. Adapted from Pasricha et al. [30] with permission from Thieme.

\section{Visibility for the Diagnostic Ability}

\subsection{Upgrade of a Capsule Endoscope Device}

The capsule endoscope system consists of a capsule for imaging, a device for receiving and storing data, a computer, and software. The pill-shaped capsule consists of a light source, a lens, a battery, and a transmission device. Capsule endoscopy can be used to observe the esophagus, stomach, small intestine, and large intestine. The capsule endoscope consists of (1) an optical dome, (2) lens, (3) light source, (4) image sensor, (5) battery, (6) transmitter, and (7) antenna.

The optical dome is made of hemispherical plastic in front of the capsule endoscope. There is an appropriate distance between the dome and the internal camera to observe the digestive tract with the mounted camera. The lens uses a single-focal lens with a small aperture. Light-emitting diodes are used as light sources to illuminate the inside of the digestive tract. Metal oxide silicon imagers use micropower to operate in low light and have many circuits integrated into a small chip.

The first capsule endoscopy system was produced by Given Imaging (Yokneam, Israel). The third-generation model PillCam SB3 (Medtronic, Washington, DC, USA) is currently used as a capsule endoscope for the small intestine. In addition, Mirocam (Intromedic, Seoul, Korea), CapsoCam (CapsoVision, Saratoga, CA, USA), EndoCapsule (Olympus, Tokyo, Japan), OMOM capsule (Jinshan Science and Technology, Chongqing, 
China) were used (Table 2). Various capsule endoscopes have been developed and used in clinical practice, but direct comparative studies on the diagnostic performance of capsule endoscopes developed by various companies have not been reported.

The first-generation PillCam SB capsule endoscope measures $11 \times 26 \mathrm{~mm}$, and both the second and third generations have the same size (Figure 7) [31,32]. The PillCam SB capsule endoscope takes two pictures per second and has a viewing angle of $140^{\circ}$. The second- and third-generation PillCam SB capsule endoscopes have an extended viewing angle of $156^{\circ}$, automatic light control, higher resolution cameras, and $12 \mathrm{~h}$ battery life.
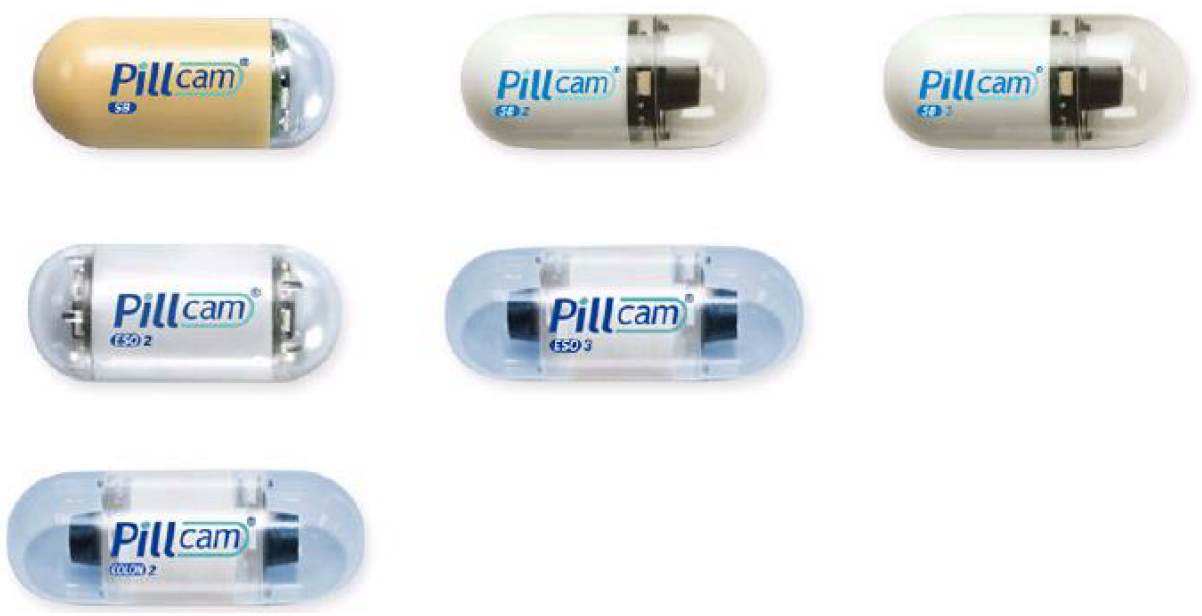

Figure 7. Pillcam Capsule endoscopy (image courtesy of Medtronic).

Intromedic (Seoul, Korea) released the MiroCam. Other capsule endoscope models use radiofrequency transmission for image transmission, but MiroCam uses human body communication to transmit information. This technology can record videos for a longer period through finer power consumption. MiroCam measures $10.8 \times 25.4 \mathrm{~mm}$, has a viewing angle of 170 degrees, takes 3-6 pictures per second, and has a battery life of $12 \mathrm{~h}$.

Introduced by CapsoVision (USA) in 2013, CapsoCam can store captured images in the capsule endoscope, eliminating the need to carry external receivers and storage devices during the examination period. In addition, CapsoCam provides a 360-degree panoramic view with four cameras arranged at $90^{\circ}$ in the middle of the capsule on the side, unlike the existing capsule endoscope with a camera at the end of the capsule. CapsoCam SV-1 can take 12-20 photos per second and store the images in the capsule itself. However, there is a disadvantage in that it is necessary to find a capsule endoscope in the patient's stool after examination and check the image taken.

Table 2. Currently available capsule endoscopy.

\begin{tabular}{|c|c|c|c|c|c|}
\hline $\begin{array}{c}\text { Capsule } \\
\text { Endoscopy }\end{array}$ & PillCam SB3 & MiroCam & CapsoCam SV-1 & Endocapsule 10 & OMOM Capsule2 \\
\hline Company & Medtronic & IntroMedic & CapsoVision & Olympus & $\begin{array}{l}\text { Jinshan Science } \\
\text { and Technology }\end{array}$ \\
\hline Size (mm) & $11 \times 26$ & $11 \times 25$ & $11 \times 31$ & $11 \times 26$ & $11 \times 25$ \\
\hline Weight $(\mathrm{g})$ & 3.0 & $3.25-4.70$ & 3.8 & 3.3 & 4.5 \\
\hline Camera lens (n) & 1 & 1 & 4 & 1 & \\
\hline Data transmission & $\begin{array}{l}\text { Radiofrequency } \\
\text { communication }\end{array}$ & $\begin{array}{l}\text { Human body } \\
\text { communication }\end{array}$ & $\mathrm{N} / \mathrm{A}$ & $\begin{array}{l}\text { Radiofrequency } \\
\text { communication }\end{array}$ & $\begin{array}{l}\text { Radiofrequency } \\
\text { communication }\end{array}$ \\
\hline Battery life (h) & 11 & 12 & 15 & 12 & 10 \\
\hline $\begin{array}{l}\text { Frame rate } \\
\text { (frames/s) }\end{array}$ & $2-6$ & $3-6$ & $12-20$ & 2 & $2-6$ \\
\hline $\begin{array}{l}\text { Field of view } \\
\text { (degree) }\end{array}$ & 156 & 170 & 360 & 160 & 165 \\
\hline US FDA approval & Yes & Yes & Yes & Yes & No \\
\hline
\end{tabular}




\subsection{Non-White Light Imaging}

White light imaging (WLI) is currently used as the principal technology in the clinical practice of capsule endoscopy. Despite recent advances in endoscopic imaging technology, capsule endoscopy has limitations in using these technological improvements. The clinical usefulness of WLI capsule endoscopy has motivated research groups to improve integrated diagnostic capability with other sensing methods. These advancements have made it possible to overcome the drawbacks of WLI capsule endoscopy through enhanced detection of gastrointestinal pathologic lesions, such as microlesions, subepithelial lesions, and transmural pathology.

To overcome the limitations of WLI, alternative imaging technologies, such as chromoendoscopy and narrow-band imaging (NBI), have been developed [33,34]. With NBI, mucosal surface patterns and superficial capillaries were observed more clearly, and blood vessels appeared black with increasing hemoglobin absorption [35]. NBI is widely used in clinical practice and actively applied to wireless capsule endoscopy in laboratory device manufacturing research [36,37]. With the routine application of endoscopic ultrasonography, the application of ultrasound to the capsule endoscope has been considered a necessary step to improve the diagnostic ability of the capsule endoscope beyond the optical image. Ultrasound capsule endoscopy (USCE) is still in its infancy, but several research teams are developing it [38-40]. Qiu et al. investigated a mechanical method using a single-element transducer powered by a vibration motor that enables radial imaging of the bowel wall (Figure 8) [41]. The frequency of the transducer plays an important role in USCE, affecting penetration depth and image resolution.

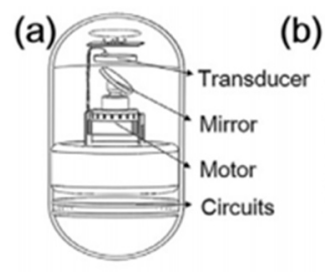

(d)
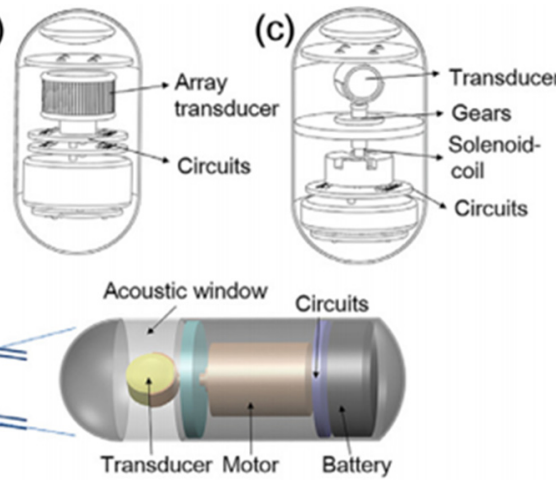

(A)

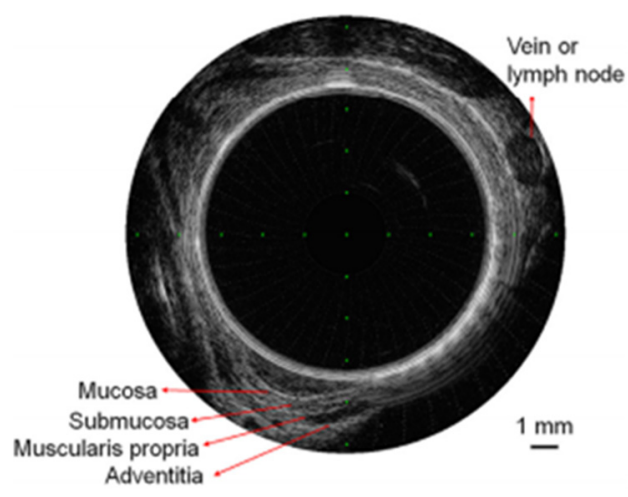

(B)

Figure 8. Illustration of ultrasound capsule. (A) (a) A mirror for ultrasound reflection. (b) Circular array transducer-based system. (c) A solenoid coil for rotating the transducer. (d) A micro-motor for rotating the transducer for circular imaging; (B) cross-sectional ultrasound image of a porcine esophagus. Adapted from Qui et al. [41] with permission from Elsevier.

Research to integrate autofluorescence imaging into capsule endoscopy has been conducted by developing several prototype imaging devices [42-44], and research on applying volumetric imaging technology to capsule endoscopy using optical coherence tomography is also being conducted $[45,46]$. In addition, in terms of biophysical measurements, studies are being conducted to measure temperature [47,48], motility [49-51], slow wave [52], and $\mathrm{pH}[53,54]$ using capsule endoscopy.

\subsection{D Reconstruction}

One of the major drawbacks of capsule endoscopy is that it is difficult to accurately measure the lesion's size. In addition, since capsule endoscopy is difficult to manipulate and inflate air, it is problematic to identify polyps or excavated lesions. To solve this problem, 3D reconstruction of capsule endoscope images has been attempted to obtain more information using current capsule endoscope images [55-58]. Koulaouzidis et al. presented a feasibility study of 3D representation software for image enhancement. They 
used a single image to investigate the accuracy of the software-based 3D reconstruction and the potential for 3D reconstruction to enhance the visualization of CE lesions. Threedimensional reconstruction is desirable for CE image reviews.

Software methods, including shape-form-shading, have been used to reconstruct the $3 \mathrm{D}$ structure of the small bowel $[59,60]$. The software approach has the basic limitation of estimating accurate and powerful 3D information without adding new image information. Although this tool has shown how useful it is in analyzing capsule images, it has limited clinical significance owing to its fundamental limitations.

Nam et al. presented a new stereo camera-based capsule endoscope (Figure 9) [61]. The device consisted of two cameras displaced by approximately $4 \mathrm{~mm}$ and four LED lights. The weight and size were comparable to those of commercially available MiroCam ${ }^{\circledR}$ capsule endoscopes. The census-based Hamming distance and absolute difference of intensities were used for stereo matching [62]. The authors evaluated the functioning and safety of the new capsule. In addition, the usefulness of 3D rendering and size measurement functions was assessed in each patient's clinical setting.
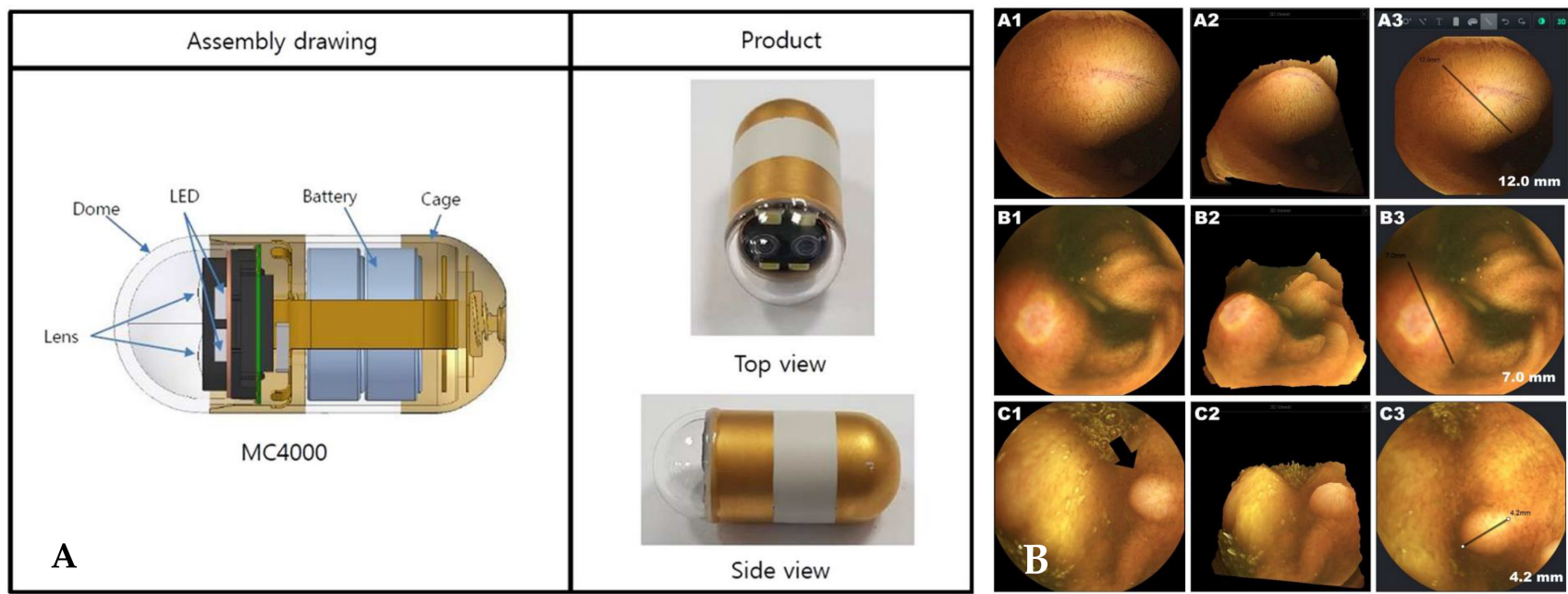

Figure 9. Stereo camera-based capsule endoscopy. (A) Illustration of MC4000 (IntroMedic ${ }^{\circledR}$ Co., Seoul, Korea); (B) images detected by MC4000. A1, B1, and C1 present conventional capsule images (A1: subepithelial lesion, B1: ulcer of Crohn's disease, and C1: polypoid lesion). A2, B2, and C2 show the 3D reconstructions of the conventional images. A3, B3, and C3 present an estimation of the lesion size. Adapted from Nam et al. [61] with permission from Springer Nature.

\section{Bowel Preparation}

During capsule endoscopy, the diagnostic yield is reduced when food remains or air bubbles are present in the small intestine. Therefore, it is important to perform proper bowel preparation and reduce bubbles in the intestine before performing capsule endoscopy [63]. Studies have been performed to increase the completion rate, small bowel visualization quality, and diagnostic yield of CE $[64,65]$. Although there are conflicting results of bowel preparation studies on capsule endoscopy, it has been reported that bowel preparation using PEG effectively improves the resolution and diagnostic rate of capsule endoscopy [65]. According to a meta-analysis of the literature on bowel preparation, use of a laxative containing PEG solution and sodium phosphate improved small bowel disease resolution and diagnosis rate. In bowel preparation for capsule endoscopy, when comparing 2 and $4 \mathrm{~L}$, there is no difference in image resolution, diagnostic rate, or complete examination rate of the study; therefore, it is generally recommended to administer PEG $2 \mathrm{~L}$.

The use of simethicone reduces intestinal bubbles and increases the resolution of capsule endoscopy. Wu et al. conducted a literature-based meta-analysis and significantly improved the resolution of the capsule endoscope in the group administered with laxatives and simethicone (OR 2.84, 95\% CI 1.74-4.65, $p=0.00$ ) [66]. Therefore, concurrent 
administration of simethicone during bowel preparation for capsule endoscopy is generally recommended [67].

In a meta-analysis of the literature analyzing the effect of administration of prokinetics during capsule endoscopy on the diagnostic yield and completion rate of capsule endoscopy, metoclopramide showed definitive test in complete test rate compared to the control group (OR 2.8, 95\% CI 1.35-3.21), and there was no difference in diagnosis rate [68]. Therefore, in patients with risk factors, prokinetics can be selectively used.

\section{Abilities of Procedure}

\subsection{Biopsy}

Another disadvantage of capsule endoscopy is that it is impossible to perform a procedure for diagnosis and treatment that can be performed with a conventional endoscope, such as a biopsy. Several issues need to be addressed for biopsy using capsule endoscopy: (1) approaching the lesion for biopsy, (2) inserting a knife or needle for biopsy of the lesion, (3) performing biopsy, and (4) retrieval of a biopsy specimen. Simi et al. presented a magnetic torsion spring mechanism using a cutting tool [69]. This device performed a histological examination using two circular cutting knives (Figure 10). In the absence of an external magnetic field, the cutting chamber was closed. When an external magnetic field was applied, the ring-shaped knife was aligned in the direction of the external magnetic field, and the chamber opened. After removing the external magnetic field, the chamber was closed, and the tissue material was obtained and placed in the chamber. Kong et al. presented a rotational micro-biopsy device using a rotational tissue-cutting razor with a strained spring [70]. This device works by releasing the strained spring near the lesion to obtain tissue and storing it in the chamber.

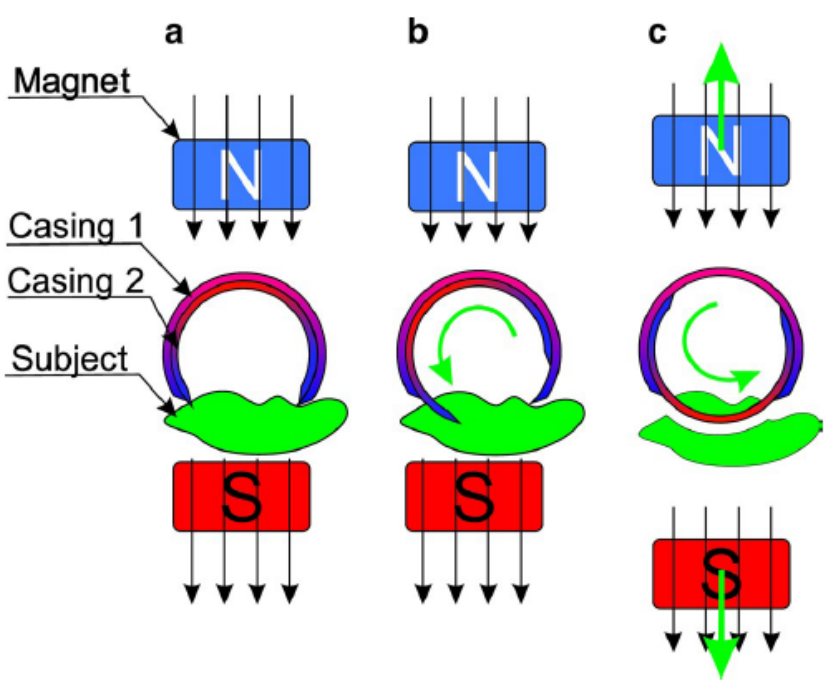

Figure 10. Magnetic torsion spring mechanism for a wireless biopsy capsule. (a) Magnetic field applied to bring the device closer to the lesion; (b) biopsy process; (c) storage of biopsy material. Adapted from Koprowski et al. [71] with permission from BMC.

\subsection{Hemostasis}

Valdastri et al. developed a novel wireless device that can perform hemostasis at a particular position using external adjustment by attaching a surgical clip (over-the-scope clip) (Figure 11) [72]. A surgical clip was attached to the distal end of the capsule endoscope, and it was made of nitinol, a biocompatible superelastic SMA. Ex vivo tests were repeated to test all the functions of the therapeutic capsule in terms of clip release efficiency and remote control reliability. 

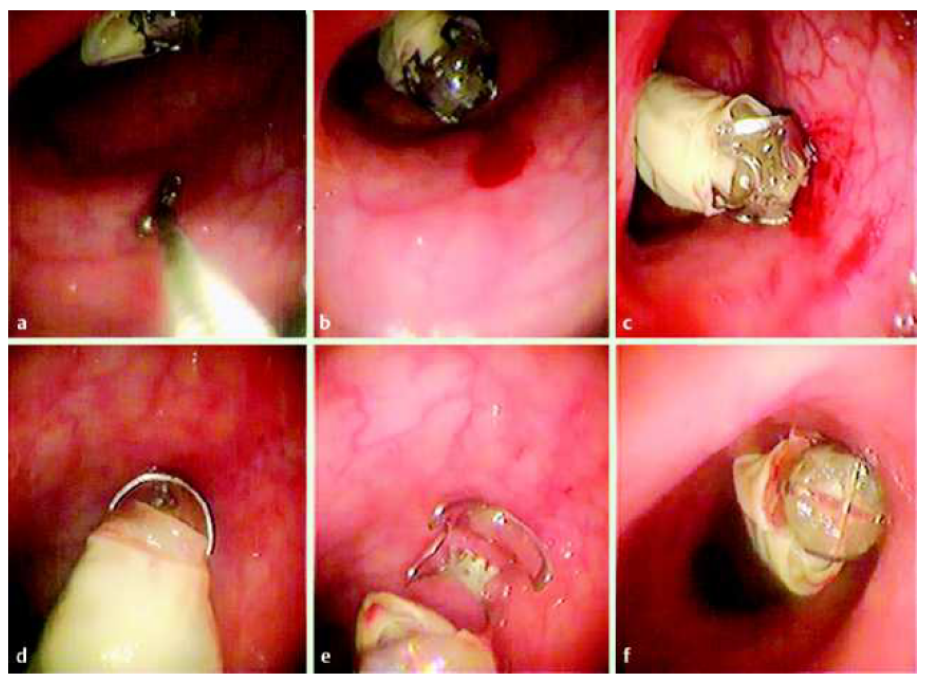

Figure 11. Wireless hemostatic endoscopic capsule. (a) Induced bleeding using a biopsy catheter; (b) the capsule approaching the bleeding lesion; (c) position adjustment using magnetic force; (d) capsule before the release of the clip; (e) deployment of the clip; (f) capsule without the clip. Adapted from Valdastri et al. [72] with permission from Thieme.

Leung et al. proposed an inflatable prototype capsule for hemostasis of the gastrointestinal tract via the balloon tamponade effect [73]. The device was composed of three segments connected by flexible joints. The capsule diameter was $14 \mathrm{~mm}$ and was surrounded by silicone rubber balloons. It inflates around hemorrhagic lesions and achieves hemostasis via the tamponade effect. Balloon inflation consists of generating gas by injecting acid into a space filled with base powder.

\section{Retention}

Capsule retention is a rare but important complication of capsule endoscopy. Capsule retention is a case in which capsules cannot be ejected for 2 weeks after administration or an intestinal obstruction occurs and surgery is required. To prevent the risk of capsule retention, a patency capsule was developed [74]. Patency capsules are made of soluble and biocompatible materials. Good patency of the intestinal tract can be checked before capsule endoscopy, and helpful information can be provided before capsule endoscopy if stenosis is suspected.

\section{Interpretation}

\subsection{Software Upgrade}

Capsule endoscopy is a convenient examination method for patients, but checking more than 50,000 images is time-consuming. After completing the capsule endoscopy, the image records stored by connecting an external storage device to the computer were analyzed and read using the software program provided by the company. The image reading program tracks the location of the intestinal tract and has a function to view continuous images from multiple sides at the same time, an enlargement function, and a function to detect bleeding and vascular suspicious lesions automatically. New functions are continuously being added (Table 3 ). The reading time varies depending on the reader's experience or the type of lesion and usually takes $30 \mathrm{~min}$ to $2 \mathrm{~h}$. Reading requires experience, and research into shortening the reading time and increasing the accuracy of diagnosis of lesions using artificial intelligence continues. 
Table 3. Comparison of software specifications.

\begin{tabular}{|c|c|c|c|c|}
\hline \multirow{4}{*}{ Software mode } & \multicolumn{2}{|c|}{ Rapid V 8.0} & \multicolumn{2}{|c|}{ MiroView 4.0} \\
\hline & $\begin{array}{l}\text { Suspected blood } \\
\text { indicator }\end{array}$ & $\begin{array}{l}\text { Video function for a quick } \\
\text { review of suspected } \\
\text { hemorrhagic lesions }\end{array}$ & Express view & $\begin{array}{l}\text { A function that helps the } \\
\text { reading by filtering out } \\
\text { overlapping images and } \\
\text { images of less importance } \\
\text { among recorded images }\end{array}$ \\
\hline & QuickView & $\begin{array}{l}\text { Ability to play clinically } \\
\text { important images to } \\
\text { provide quick preview and } \\
\text { location }\end{array}$ & SGIB & $\begin{array}{l}\text { A function to help the } \\
\text { reading of suspected } \\
\text { bleeding lesions }\end{array}$ \\
\hline & $\begin{array}{c}\text { Complementary } \\
\text { QuickView }\end{array}$ & $\begin{array}{l}\text { A mode that plays back } \\
\text { videos not provided in } \\
\text { QuickView mode. }\end{array}$ & & \\
\hline
\end{tabular}

\subsection{Artificial Intelligence}

Recently, with the development of artificial intelligence, several researchers have reported the potential application of convolutional neural network (CNN) systems to diagnose various small bowel lesions. The application of this artificial intelligence capsule endoscope will reduce the time required for capsule endoscope interpretation. With the development of deep learning algorithms, the $\mathrm{CNN}$, which obtains specific characteristics by polling and convolutional layers and performs back-propagation to create the best feature map, has become the main deep learning algorithm for image analysis $[75,76]$. Aoki et al. presented a study for finding mucosal erosion and ulcers with a CNN-based program and manually annotated more than 5000 capsule endoscopy images [77]. This program model presented promising functioning with an area under the receiver-operating characteristic curve (AUROC) of 0.958 , an accuracy of $90.8 \%$, a sensitivity of $88.2 \%$, and a specificity of $90.9 \%$.

Klang et al. presented a CNN model for detecting ulcers in Crohn's disease using 17,000 capsule endoscopy images [78]. This CNN model using 5-fold cross-validation showed an AUROC of 0.99 , an accuracy of $96.7 \%$, a sensitivity of $96.8 \%$, and a specificity of $96.6 \%$.

Saito et al. developed a CNN model with 30,584 images to detect and classify protruding lesions [79]. This model presented an AUROC of 0.911 , a sensitivity of $90.7 \%$, and a specificity of $79.8 \%$. For classification, sensitivities of $86.5 \%, 92.0 \%, 95.8 \%, 77.0 \%$, and $94.4 \%$ were noted for polyps, nodules, epithelial tumors, submucosal tumors, and venous structures, respectively.

\section{Conclusions}

Wireless capsule endoscopy has become a routine examination in clinical practice for investigating the gastrointestinal tract. Although capsule endoscopy has several limitations, studies by several researchers to overcome these shortcomings are ongoing. For more effective technological advancement, both engineers and clinicians need to participate.

The usefulness of capsule endoscopy is emphasized because it is less invasive and is convenient during the procedure. Such usefulness will become more prominent over time.

Studies to overcome the limitations of capsule endoscopy are meaningful separately; however, they will eventually be integrated into one to bring about greater synergy. However, most of the technological advances described above are still in their infancy, and thus it is necessary to verify the efficacy of technological advances through the human application.

Author Contributions: Writing—original draft preparation and conceptualization, S.H.K.; resources, validation, and methodology; writing — review and editing: H.J.C. All authors have read and agreed to the published version of the manuscript. 
Funding: This research was supported by the National Research Foundation of Korea (NRF) grant funded by the Korean Government (NRF-2019R1C1C1009819) and by a grant from the Korea University, Seoul, Republic of Korea (grant no. K1924971).

Institutional Review Board Statement: Not applicable.

Informed Consent Statement: Not applicable.

Data Availability Statement: Not applicable.

Conflicts of Interest: The authors declare no conflict of interest.

\section{References}

1. Iddan, G.; Meron, G.; Glukhovsky, A.; Swain, P. Wireless capsule endoscopy. Nature 2000, 405, 417. [CrossRef]

2. Soncini, M.; Girelli, C.M.; de Franchis, R.; Rondonotti, E. Small-Bowel Capsule Endoscopy in Clinical Practice: Has Anything Changed Over 13 Years? Dig. Dis. Sci. 2018, 63, 2244-2250. [CrossRef]

3. Kharazmi, A.A.; Aslani, S.; Kristiansen, M.F.; Dahl, E.E.; Berner-Hansen, M. Indications and diagnostic yield of small-bowel capsule endoscopy in a real-world setting. BMC Gastroenterol. 2020, 20, 177. [CrossRef]

4. Liao, Z.; Gao, R.; Xu, C.; Li, Z.S. Indications and detection, completion, and retention rates of small-bowel capsule endoscopy: A systematic review. Gastrointest. Endosc. 2010, 71, 280-286. [CrossRef] [PubMed]

5. Chetcuti Zammit, S.; Sidhu, R. Capsule endoscopy-Recent developments and future directions. Expert Rev. Gastroenterol. Hepatol. 2021, 15, 127-137. [CrossRef]

6. Enns, R.A.; Hookey, L.; Armstrong, D.; Bernstein, C.N.; Heitman, S.J.; Teshima, C.; Leontiadis, G.I.; Tse, F.; Sadowski, D. Clinical Practice Guidelines for the Use of Video Capsule Endoscopy. Gastroenterology 2017, 152, 497-514. [CrossRef] [PubMed]

7. Hale, M.F.; Sidhu, R.; McAlindon, M.E. Capsule endoscopy: Current practice and future directions. World J. Gastroenterol. 2014, 20, 7752-7759. [CrossRef] [PubMed]

8. Neumann, H.; Fry, L.C.; Neurath, M.F. Review article on current applications and future concepts of capsule endoscopy. Digestion 2013, 87, 91-99. [CrossRef]

9. Goenka, M.K.; Majumder, S.; Goenka, U. Capsule endoscopy: Present status and future expectation. World J. Gastroenterol. 2014, 20, 10024-10037. [CrossRef]

10. Yang, H.; Zhang, Y.; Liu, Z.; Liu, X.; Liu, G. Posture Dynamic Modeling and Stability Analysis of a Magnetic Driven Dual-Spin Spherical Capsule Robot. Micromachines 2021, 12, 238. [CrossRef]

11. Lewis, B.S.; Eisen, G.M.; Friedman, S. A pooled analysis to evaluate results of capsule endoscopy trials. Endoscopy 2005, 37, 960-965. [CrossRef] [PubMed]

12. Grady, M.S.; Howard, M.A., III; Dacey, R.G., Jr.; Blume, W.; Lawson, M.; Werp, P.; Ritter, R.C. Experimental study of the magnetic stereotaxis system for catheter manipulation within the brain. J. Neurol. Surg. 2000, 93, 282-288. [CrossRef]

13. Filgueiras-Rama, D.; Estrada, A.; Shachar, J.; Castrejón, S.; Doiny, D.; Ortega, M.; Gang, E.; Merino, J.L. Remote magnetic navigation for accurate, real-time catheter positioning and ablation in cardiac electrophysiology procedures. J. Vis. Exp. 2013, 74, 3658. [CrossRef]

14. Shamsudhin, N.; Zverev, V.I.; Keller, H.; Pane, S.; Egolf, P.W.; Nelson, B.J.; Tishin, A.M. Magnetically guided capsule endoscopy. Med. Phys. 2017, 44, e91-e111. [CrossRef] [PubMed]

15. Swain, P.; Toor, A.; Volke, F.; Keller, J.; Gerber, J.; Rabinovitz, E.; Rothstein, R.I. Remote magnetic manipulation of a wireless capsule endoscope in the esophagus and stomach of humans (with videos). Gastrointest. Endosc. 2010, 71, 1290-1293. [CrossRef]

16. Rahman, I.; Afzal, N.A.; Patel, P. The role of magnetic assisted capsule endoscopy (MACE) to aid visualisation in the upper GI tract. Comput. Biol. Med. 2015, 65, 359-363. [CrossRef] [PubMed]

17. Liao, Z.; Hou, X.; Lin-Hu, E.Q.; Sheng, J.Q.; Ge, Z.Z.; Jiang, B.; Hou, X.H.; Liu, J.Y.; Li, Z.; Huang, Q.Y.; et al. Accuracy of Magnetically Controlled Capsule Endoscopy, Compared With Conventional Gastroscopy, in Detection of Gastric Diseases. Clin. Gastroenterol. Hepatol. 2016, 14, 1266-1273.e1. [CrossRef] [PubMed]

18. Ching, H.L.; Hale, M.F.; Sidhu, R.; Beg, S.; Ragunath, K.; McAlindon, M.E. Magnetically assisted capsule endoscopy in suspected acute upper GI bleeding versus esophagogastroduodenoscopy in detecting focal lesions. Gastrointest. Endosc. 2019, 90, 430-439. [CrossRef] [PubMed]

19. Rahman, I.; Pioche, M.; Shim, C.S.; Lee, S.P.; Sung, I.K.; Saurin, J.C.; Patel, P. Magnetic-assisted capsule endoscopy in the upper GI tract by using a novel navigation system (with video). Gastrointest. Endosc. 2016, 83, 889-895.e1. [CrossRef]

20. Carpi, F.; Galbiati, S.; Carpi, A. Controlled navigation of endoscopic capsules: Concept and preliminary experimental investigations. IEEE Trans. BioMed. Eng. 2007, 54, 2028-2036. [CrossRef]

21. Glass, P.; Cheung, E.; Sitti, M. A legged anchoring mechanism for capsule endoscopes using micropatterned adhesives. IEEE Trans. BioMed. Eng. 2008, 55, 2759-2767. [CrossRef] [PubMed]

22. Kim, H.M.; Yang, S.; Kim, J.; Park, S.; Cho, J.H.; Park, J.Y.; Kim, T.S.; Yoon, E.S.; Song, S.Y.; Bang, S. Active locomotion of a paddling-based capsule endoscope in an in vitro and in vivo experiment (with videos). Gastrointest. Endosc. 2010, 72, 381-387. [CrossRef] 
23. Park, S.; Park, H.; Park, S.; Jee, C.; Kim, J.; Kim, B. Capsular locomotive microrobot for gastrointestinal tract. In Proceedings of the 2006 International Conference of the IEEE Engineering in Medicine and Biology Society, New York, NY, USA, 30 August-3 September 2006; pp. 2211-2214. [CrossRef]

24. Yang, S.; Park, K.; Kim, J.; Kim, T.S.; Cho, I.J.; Yoon, E.S. Autonomous locomotion of capsule endoscope in gastrointestinal tract. In Proceedings of the 2011 Annual International Conference of the IEEE Engineering in Medicine and Biology Society, Boston, MA, USA, 30 August-3 September 2011; pp. 6659-6663. [CrossRef]

25. Liu, L.; Towfighian, S.; Hila, A. A Review of Locomotion Systems for Capsule Endoscopy. IEEE Rev. Biomed. Eng. 2015, 8, 138-151. [CrossRef] [PubMed]

26. Cheung, E.; Karagozler, M.E.; Park, S.; Kim, B.; Sitti, M. A New Endoscopic Microcapsule Robot using Beetle Inspired Microfibrillar Adhesives. In Proceedings of the 2005 IEEE/ASME International Conference on Advanced Intelligent Mechatronics, Monterey, CA, USA, 24-28 July 2005; pp. 551-557.

27. Karagozler, M.E.; Cheung, E.; Jiwoon, K.; Sitti, M. Miniature Endoscopic Capsule Robot using Biomimetic Micro-Patterned Adhesives. In Proceedings of the First IEEE/RAS-EMBS International Conference on Biomedical Robotics and Biomechatronics, Pisa, Italy, 20-22 February 2006; Volume 2006, pp. 105-111.

28. Nam, S.-J.; Lee, H.S.; Lim, Y.J. Evaluation of Gastric Disease with Capsule Endoscopy. Clin. Endosc. 2018, 51, 323-328. [CrossRef]

29. Gorlewicz, J.L.; Battaglia, S.; Smith, B.F.; Ciuti, G.; Gerding, J.; Menciassi, A.; Obstein, K.L.; Valdastri, P.; Webster, R.J., III. Wireless insufflation of the gastrointestinal tract. IEEE Trans. BioMed. Eng. 2013, 60, 1225-1233. [CrossRef] [PubMed]

30. Pasricha, T.; Smith, B.F.; Mitchell, V.R.; Fang, B.; Brooks, E.R.; Gerding, J.S.; Washington, M.K.; Valdastri, P.; Obstein, K.L. Controlled colonic insufflation by a remotely triggered capsule for improved mucosal visualization. Endoscopy 2014, 46, 614-618. [CrossRef]

31. Hosoe, N.; Takabayashi, K.; Ogata, H.; Kanai, T. Capsule endoscopy for small-intestinal disorders: Current status. Dig. Endosc. 2019, 31, 498-507. [CrossRef]

32. Omori, T.; Hara, T.; Sakasai, S.; Kambayashi, H.; Murasugi, S.; Ito, A.; Nakamura, S.; Tokushige, K. Does the PillCam SB3 capsule endoscopy system improve image reading efficiency irrespective of experience? A pilot study. Endosc. Int. Open 2018, 6, E669-E675. [CrossRef]

33. Har-Noy, O.; Katz, L.; Avni, T.; Battat, R.; Bessissow, T.; Yung, D.E.; Engel, T.; Koulaouzidis, A.; Eliakim, R.; Ben-Horin, S.; et al. Chromoendoscopy, Narrow-Band Imaging or White Light Endoscopy for Neoplasia Detection in Inflammatory Bowel Diseases. Dig. Dis. Sci. 2017, 62, 2982-2990. [CrossRef]

34. Hoffman, A.; Manner, H.; Rey, J.W.; Kiesslich, R. A guide to multimodal endoscopy imaging for gastrointestinal malignancy-An early indicator. Nat. Rev. Gastroenterol. Hepatol. 2017, 14, 421-434. [CrossRef] [PubMed]

35. Gono, K. Narrow Band Imaging: Technology Basis and Research and Development History. Clin. Endosc. 2015, 48, 476-480. [CrossRef] [PubMed]

36. Yen, C.-T.; Lai, Z.-W.; Lin, Y.-T.; Cheng, H.-C. Optical Design with Narrow-Band Imaging for a Capsule Endoscope. J. Healthc. Eng. 2018, 2018, 5830759. [CrossRef] [PubMed]

37. Khan, T.H.; Wahid, K.A. White and narrow band image compressor based on a new color space for capsule endoscopy. Signal Process. Image Commun. 2014, 29, 345-360. [CrossRef]

38. Wang, J.; Memon, F.; Touma, G.; Baltsavias, S.; Jang, J.H.; Chang, C.; Rasmussen, M.F.; Olcott, E.; Jeffrey, R.B.; Arbabian, A.; et al. Capsule ultrasound device: Characterization and testing results. In Proceedings of the 2017 IEEE International Ultrasonics Symposium (IUS), Washington, DC, USA, 6-9 September 2017; pp. 1-4.

39. Wang, X.; Seetohul, V.; Chen, R.; Zhang, Z.; Qian, M.; Shi, Z.; Yang, G.; Mu, P.; Wang, C.; Huang, Z.; et al. Development of a Mechanical Scanning Device With High-Frequency Ultrasound Transducer for Ultrasonic Capsule Endoscopy. IEEE Trans. Med. Imaging 2017, 36, 1922-1929. [CrossRef]

40. Cox, B.F.; Stewart, F.; Lay, H.; Cummins, G.; Newton, I.P.; Desmulliez, M.P.Y.; Steele, R.J.C.; Näthke, I.; Cochran, S. Ultrasound capsule endoscopy: Sounding out the future. Ann. Transl. Med. 2017, 5, 201. [CrossRef]

41. Qiu, Y.; Huang, Y.; Zhang, Z.; Cox, B.F.; Liu, R.; Hong, J.; Mu, P.; Lay, H.S.; Cummins, G.; Desmulliez, M.P.Y.; et al. Ultrasound Capsule Endoscopy With a Mechanically Scanning Micro-ultrasound: A Porcine Study. Ultrasound Med. Biol. 2020, 46, 796-804. [CrossRef]

42. Al-Rawhani, M.A.; Beeley, J.; Cumming, D.R. Wireless fluorescence capsule for endoscopy using single photon-based detection. Sci. Rep. 2015, 5, 18591. [CrossRef] [PubMed]

43. Demosthenous, P.; Pitris, C.; Georgiou, J. Infrared Fluorescence-Based Cancer Screening Capsule for the Small Intestine. IEEE Trans. Biomed. Circuits Syst. 2016, 10, 467-476. [CrossRef]

44. Nemiroski, A.; Ryou, M.; Thompson, C.C.; Westervelt, R.M. Swallowable fluorometric capsule for wireless triage of gastrointestinal bleeding. Lab Chip 2015, 15, 4479-4487. [CrossRef]

45. Gora, M.J.; Sauk, J.S.; Carruth, R.W.; Gallagher, K.A.; Suter, M.J.; Nishioka, N.S.; Kava, L.E.; Rosenberg, M.; Bouma, B.E.; Tearney, G.J. Tethered capsule endomicroscopy enables less invasive imaging of gastrointestinal tract microstructure. Nat. Med. 2013, 19, 238-240. [CrossRef]

46. Liang, K.; Traverso, G.; Lee, H.C.; Ahsen, O.O.; Wang, Z.; Potsaid, B.; Giacomelli, M.; Jayaraman, V.; Barman, R.; Cable, A.; et al. Ultrahigh speed en face OCT capsule for endoscopic imaging. Biomed. Opt. Express 2015, 6, 1146-1163. [CrossRef] 
47. Stewart, I.B.; Stewart, K.L.; Worringham, C.J.; Costello, J.T. Physiological tolerance times while wearing explosive ordnance disposal protective clothing in simulated environmental extremes. PLoS ONE 2014, 9, e83740. [CrossRef] [PubMed]

48. Niedermann, R.; Wyss, E.; Annaheim, S.; Psikuta, A.; Davey, S.; Rossi, R.M. Prediction of human core body temperature using non-invasive measurement methods. Int. J. Biometeorol. 2014, 58, 7-15. [CrossRef] [PubMed]

49. Stein, E.; Berger, Z.; Hutfless, S.; Shah, L.; Wilson, L.M.; Haberl, E.B.; Bass, E.B.; Clarke, J.O. AHRQ Comparative Effectiveness Reviews. Wireless Motility Capsule Versus Other Diagnostic Technologies for Evaluating Gastroparesis and Constipation: A Comparative Effectiveness Review; Agency for Healthcare Research and Quality: Rockville, MD, USA, 2013.

50. Li, P.; Kreikemeier-Bower, C.; Xie, W.; Kothari, V.; Terry, B.S. Design of a Wireless Medical Capsule for Measuring the Contact Pressure Between a Capsule and the Small Intestine. J. Biomech. Eng. 2017, 139, 051003. [CrossRef] [PubMed]

51. Saad, R.J. The Wireless Motility Capsule: A One-Stop Shop for the Evaluation of GI Motility Disorders. Curr. Gastroenterol. Rep. 2016, 18, 14. [CrossRef] [PubMed]

52. Woo, S.H.; Cho, J.H. Telemetry system for slow wave measurement from the small bowel. Med. Biol. Eng. Comput. 2010, 48, 277-283. [CrossRef]

53. Hochman, J.A.; Favaloro-Sabatier, J. Tolerance and reliability of wireless pH monitoring in children. J. Pediatr. Gastroenterol. Nutr. 2005, 41, 411-415. [CrossRef]

54. Koziolek, M.; Grimm, M.; Becker, D.; Iordanov, V.; Zou, H.; Shimizu, J.; Wanke, C.; Garbacz, G.; Weitschies, W. Investigation of $\mathrm{pH}$ and Temperature Profiles in the GI Tract of Fasted Human Subjects Using the Intellicap ${ }^{\circledR}$ System. J. Pharm. Sci. 2015, 104, 2855-2863. [CrossRef]

55. Koulaouzidis, A.; Karargyris, A.; Rondonotti, E.; Noble, C.L.; Douglas, S.; Alexandridis, E.; Zahid, A.M.; Bathgate, A.J.; Trimble, K.C.; Plevris, J.N. Three-dimensional representation software as image enhancement tool in small-bowel capsule endoscopy: A feasibility study. Dig. Liver Dis. 2013, 45, 909-914. [CrossRef]

56. Rondonotti, E.; Koulaouzidis, A.; Karargyris, A.; Giannakou, A.; Fini, L.; Soncini, M.; Pennazio, M.; Douglas, S.; Shams, A.; Lachlan, N.; et al. Utility of 3-dimensional image reconstruction in the diagnosis of small-bowel masses in capsule endoscopy (with video). Gastrointest. Endosc. 2014, 80, 642-651. [CrossRef]

57. Turan, M.; Pilavci, Y.; Jamiruddin, R.; Araujo, H.; Konukoglu, E.; Sitti, M. A Fully Dense and Globally Consistent 3D Map Reconstruction Approach for GI Tract to Enhance Therapeutic Relevance of the Endoscopic Capsule Robot. arXiv 2017, arXiv:1705.06524.

58. Prasath, V.B.S.; Figueiredo, I.N.; Figueiredo, P.N.; Palaniappan, K. Mucosal region detection and 3D reconstruction in wireless capsule endoscopy videos using active contours. In Proceedings of the 2012 Annual International Conference of the IEEE Engineering in Medicine and Biology Society, San Diego, CA, USA, 28 August-1 September 2012; pp. 4014-4017.

59. Koulaouzidis, A.; Karargyris, A. Three-dimensional image reconstruction in capsule endoscopy. World J. Gastroenterol. 2012, 18, 4086-4090. [CrossRef] [PubMed]

60. Karargyris, A.; Rondonotti, E.; Mandelli, G.; Koulaouzidis, A. Evaluation of 4 three-dimensional representation algorithms in capsule endoscopy images. World J. Gastroenterol. 2013, 19, 8028-8033. [CrossRef]

61. Nam, S.J.; Lim, Y.J.; Nam, J.H.; Lee, H.S.; Hwang, Y.; Park, J.; Chun, H.J. 3D reconstruction of small bowel lesions using stereo camera-based capsule endoscopy. Sci. Rep. 2020, 10, 6025. [CrossRef]

62. Mei, X.; Sun, X.; Zhou, M.; Jiao, S.; Wang, H.; Xiaopeng, Z. On building an accurate stereo matching system on graphics hardware. In Proceedings of the 2011 IEEE International Conference on Computer Vision Workshops (ICCV Workshops), Barcelona, Spain, 6-13 November 2011; pp. 467-474.

63. Viazis, N.; Sgouros, S.; Papaxoinis, K.; Vlachogiannakos, J.; Bergele, C.; Sklavos, P.; Panani, A.; Avgerinos, A. Bowel preparation increases the diagnostic yield of capsule endoscopy: A prospective, randomized, controlled study. Gastrointest. Endosc. 2004, 60, 534-538. [CrossRef]

64. Ladas, S.D.; Triantafyllou, K.; Spada, C.; Riccioni, M.E.; Rey, J.F.; Niv, Y.; Delvaux, M.; de Franchis, R.; Costamagna, G. European Society of Gastrointestinal Endoscopy (ESGE): Recommendations (2009) on clinical use of video capsule endoscopy to investigate small-bowel, esophageal and colonic diseases. Endoscopy 2010, 42, 220-227. [CrossRef]

65. Rokkas, T.; Papaxoinis, K.; Triantafyllou, K.; Pistiolas, D.; Ladas, S.D. Does purgative preparation influence the diagnostic yield of small bowel video capsule endoscopy?: A meta-analysis. Am. J. Gastroenterol. 2009, 104, 219-227. [CrossRef]

66. Wu, L.; Cao, Y.; Liao, C.; Huang, J.; Gao, F. Systematic review and meta-analysis of randomized controlled trials of Simethicone for gastrointestinal endoscopic visibility. Scand. J. Gastroenterol. 2011, 46, 227-235. [CrossRef]

67. Rondonotti, E.; Spada, C.; Adler, S.; May, A.; Despott, E.J.; Koulaouzidis, A.; Panter, S.; Domagk, D.; Fernandez-Urien, I.; Rahmi, G.; et al. Small-bowel capsule endoscopy and device-assisted enteroscopy for diagnosis and treatment of small-bowel disorders: European Society of Gastrointestinal Endoscopy (ESGE) Technical Review. Endoscopy 2018, 50, 423-446. [CrossRef]

68. Koulaouzidis, A.; Giannakou, A.; Yung, D.E.; Dabos, K.J.; Plevris, J.N. Do prokinetics influence the completion rate in small-bowel capsule endoscopy? A systematic review and meta-analysis. Curr. Med. Res. Opin. 2013, 29, 1171-1185. [CrossRef] [PubMed]

69. Simi, M.; Gerboni, G.; Menciassi, A.; Valdastri, P. Magnetic Torsion Spring Mechanism for a Wireless Biopsy Capsule. J. Med. Devices 2013, 7, 041009. [CrossRef]

70. Kyoung-chul, K.; Jinhoon, C.; Doyoung, J.; Dong-il Dan, C. A rotational micro biopsy device for the capsule endoscope. In Proceedings of the 2005 IEEE/RSJ International Conference on Intelligent Robots and Systems, Edmonton, AB, Canada, 2-6 August 2005; pp. 1839-1843. 
71. Koprowski, R. Overview of technical solutions and assessment of clinical usefulness of capsule endoscopy. Biomed. Eng. OnLine 2015, 14, 111. [CrossRef]

72. Valdastri, P.; Quaglia, C.; Susilo, E.; Menciassi, A.; Dario, P.; Ho, C.N.; Anhoeck, G.; Schurr, M.O. Wireless therapeutic endoscopic capsule: In vivo experiment. Endoscopy 2008, 40, 979-982. [CrossRef] [PubMed]

73. Leung, B.H.K.; Poon, C.C.Y.; Zhang, R.; Zheng, Y.; Chan, C.K.W.; Chiu, P.W.Y.; Lau, J.Y.W.; Sung, J.J.Y. A Therapeutic Wireless Capsule for Treatment of Gastrointestinal Haemorrhage by Balloon Tamponade Effect. IEEE Trans. BioMed. Eng. 2017, 64, 1106-1114. [CrossRef] [PubMed]

74. Römmele, C.; Brueckner, J.; Messmann, H.; Gölder, S.K. Clinical Experience with the PillCam Patency Capsule prior to Video Capsule Endoscopy: A Real-World Experience. Gastroenterol. Res. Pract. 2016, 2016, 9657053. [CrossRef] [PubMed]

75. Chao, W.L.; Manickavasagan, H.; Krishna, S.G. Application of Artificial Intelligence in the Detection and Differentiation of Colon Polyps: A Technical Review for Physicians. Diagnostics 2019, 9, 99. [CrossRef] [PubMed]

76. Yang, Y.J. The Future of Capsule Endoscopy: The Role of Artificial Intelligence and Other Technical Advancements. Clin. Endosc. 2020, 53, 387-394. [CrossRef] [PubMed]

77. Aoki, T.; Yamada, A.; Aoyama, K.; Saito, H.; Tsuboi, A.; Nakada, A.; Niikura, R.; Fujishiro, M.; Oka, S.; Ishihara, S.; et al. Automatic detection of erosions and ulcerations in wireless capsule endoscopy images based on a deep convolutional neural network. Gastrointest. Endosc. 2019, 89, 357-363.e2. [CrossRef]

78. Klang, E.; Barash, Y.; Margalit, R.Y.; Soffer, S.; Shimon, O.; Albshesh, A.; Ben-Horin, S.; Amitai, M.M.; Eliakim, R.; Kopylov, U. Deep learning algorithms for automated detection of Crohn's disease ulcers by video capsule endoscopy. Gastrointest. Endosc. 2020, 91, 606-613. [CrossRef]

79. Saito, H.; Aoki, T.; Aoyama, K.; Kato, Y.; Tsuboi, A.; Yamada, A.; Fujishiro, M.; Oka, S.; Ishihara, S.; Matsuda, T.; et al. Automatic detection and classification of protruding lesions in wireless capsule endoscopy images based on a deep convolutional neural network. Gastrointest. Endosc. 2020, 92, 144-151.e1. [CrossRef] 